\title{
Leitura crítica da Educação baseada em competências
}

\author{
Carlindo de Lira Pereira ${ }^{1}$ \\ ${ }^{1}$ Mestre em Ciências da Educação pela UNINTER e docente da Universidade Estadual \\ de Alagoas - UNEAL. E-mail: carlindolira@uneal.edu.br
}

Resumo - Diante dos novos desafios proporcionados pela revolução industrial e a consequente avalanche de produção de conhecimento que sucedeu a nova forma de organização social, tornou-se imperativo a produção, numa escala sem igual na história da humanidade, de informação veiculada pelos mass midea para dar conta dos crescentes contingentes urbanos industriais concentrados nas grandes cidades e, por outro lado, da necessidade imposta pela produção em massa da sociedade capitalista, de produzir, sem cessar, o conhecimento necessário para atender as demandas de consumo em larga escala desse modelo de organização social, que se estruturou ao longo do século XX, fez surgir uma nova proposta de educação baseada, agora, em competências e habilidades.

Palavras-chave: informação; conhecimento; competências; habilidades.

\begin{abstract}
In view of the new challenges brought about by the industrial revolution and the resulting avalanche of knowledge production that followed the new form of social organization, it became imperative to produce, on a scale unparalleled in human history, information conveyed by the mass media to account for the growing industrial urban contingents concentrated in large cities and, on the other hand, the need imposed by the mass production of capitalist society, to continuously produce the knowledge necessary to meet the demands of large-scale consumption of this model of social organization, which was structured throughout the 20th century, gave rise to a new proposal for education based, now, on competences and skills.
\end{abstract}

Keywords: information; knowledge; Skills; skills. 


\section{Introdução}

O modelo de educação parece caminhar de braços dados com os desafios propostos pelo tipo de organização social e econômica de uma dada comunidade, que faz opção por um determinado modus vivendus. Daí, surgem os desafios face ao modo de produção adotado, que demanda novas estratégias a serem pensadas, estudadas, desenvolvidas e aplicadas para a obtenção dos resultados necessários à sobrevivência face aos novos desafios dos novos tempos.

O século XX sofreu um processo de mudanças em todos os aspectos da vida moderna, fazendo surgir um novo cenário mundial sociopolítico-econômico alterando profundamente a relação de forças no mundo, o que promoveu o valor do pensamento pedagógico como estratégia de crescimento, e nesse novíssimo contexto a escola tornou-se fator preponderante de transformação para a preparação das novas gerações diante de desafios jamais enfrentados.

O pensamento da educação baseada em competências emerge desse contexto da sociedade da informação, que exige do cidadão trabalhador competências diferentes daquelas do modelo da sociedade pautada numa produção prioritariamente agrícola; com a revolução industrial, requer-se que a nova força de trabalho nas fábricas, indústrias e no setor terciário tenham competência para a leitura, compreensão e interpretação de manuais técnicos e para pôr em funcionamento maquinários com grau de complexidade cada vez mais crescente, até o advento do computador presente em toda a cadeia de produção da sociedade capitalista, até mesmo no meio rural, exigindo de todos educação digital, informatização, como fator preponderante para alcançar suas metas.

A definição dos conceitos de habilidades e competências variam conforme o perfil que os pesquisadores dão aos seus estudos. Paul Attewell (1993, apud in UNESCO) diz ser um conceito profundamente complicado, mas, por outro lado, Richard Boyatzis (1997, apud in UNESCO) define: "uma competência é a destreza para demonstrar a sequência de um sistema de comportamento que funcionalmente está relacionado com o desempenho ou com o resultado proposto para alcançar uma meta, e deve ser algo observável, algo que uma pessoa dentro do convívio social pode observar e julgar".

Por sua vez, os valores representam o contexto no qual as habilidades e a aplicação dos conhecimentos se baseiam, para Astin (1993, apud in Villalba) "um valor é um princípio abstrato e generalizado do comportamento que provê normas para julgar algumas ações e metas específicas, as quais fazem os membros de um grupo sentir um forte compromisso emocional". 


\section{Os conteúdos da aprendizagem na educação baseada em competências}

Diferentemente do ensino tradicional que apresenta na escola um conteúdo dissociado do meio social, teoricamente universal e sem inserção na realidade da comunidade escolar, portanto estático. Os conteúdos da aprendizagem baseado em competências atribui a escola valores e funções em sintonia com um contexto sociohistórico determinado.

Nessa linha de pensamento Jimeno Sacristán (1998) aponta Três considerações importantes para a elaboração do conteúdo proposto para a aprendizagem escolar: primeiro, o que deve ocupar o tempo escolar tem que ser algo mais do que as acepções clássicas da cultura acadêmica tradicional; segundo, no ensino não se transmite apenas Literatura, História ou Ciências Físicas, mas deve-se possibilitar o desenvolvimento pleno da pessoa humana em todas as suas dimensões; terceiro, se o currículo é uma seleção de conteúdos da cultura, nesse caso cabe indagar sobre o conceito de cultura que se almeja, e uma das acepções é a antropológica, como um conjunto de significados do tipo intelectual, ético, estético, social, técnico, mítico, comportamental, etc. que caracteriza um grupo social.

O currículo, nessa acepção, deve refletir sempre o projeto de sociedade proposto pelo conjunto da sociedade organizada. Sendo assim, entende-se por conteúdos o conjunto de formas culturais e de saberes selecionados em torno do qual deve se organizar as atividades em sala de aula.

\section{Tipos de conteúdos}

Para Zavala (2000) os conteúdos apresentam certas características e podem ser divididos em Conceituais, que se subdivide em factuais, conceitos ou princípios; por conteúdos factuais entende-se o conhecimento dos fatos, acontecimentos, situações e fenômenos concretos e singulares; já os conceitos ou princípios fazem referência ao conjunto de objetos ou símbolos que têm características semelhantes. Não se pode dizer que um conceito ou princípio foi aprendido, mas apenas compreendido os significados dos mesmos.

Outro conteúdo, é o procedimental, ou seja, habilidades, destrezas e estratégias; por isso, são concebidos como um agregado de ações ordenadas para o consecução de um objetivo. Logo, os conteúdos procedimentais devem propor várias atividades para o 
aluno realizar, tais como imitação de modelos, ensino direto guiando a prática do aluno e levando o aluno a analisar e refletir sobre suas ações.

Para Coll (1992) deve haver também conteúdos atitudinais que dizem respeito aos valores e normas e que, por sua vez, tem três componentes imprescindíveis: o cognitivo, o afetivo e o de conduta. Logo, como conteúdo de ensino deve fazer parte de todas as disciplinas, facilitando, assim, a aquisição de outros conhecimentos.

Como as atitudes apresentam-se dinamicamente, são mais difíceis de avaliar se houve realmente aprendizagem, que pode ser testada a partir do exemplo, da observação, da imitação etc., evidentemente para que tal ocorra a contento deve-se considerar alguns critérios no ato de ensino dos conteúdos, que são: adequação entre atitudes, valores e normas; preparação do ambiente ou do espaço-temporal para que seja pertinente; que as atividades didáticas sejam em grupo; e, por fim, dedicar tempo à resolução de problemas individuais e coletivos.

\section{Papel do docente na condução da aprendizagem}

Na concepção tradicional de ensino cabia ao professor apenas "dar aula", isto é, expor o conteúdo aos alunos, transmitir o conteúdo. Já na proposta fundamentada numa aprendizagem por competências esse papel é ampliado e diversificado. O professor não é visto apenas como aquele que sabe um conteúdo, expõe e cobra numa prova, tal qual ele falou ou escreveu, ipsis literis.

$\mathrm{O}$ ensino fundamentado numa aprendizagem por competências exige um novo papel para a atuação docente, agora este deve estimular a participação ativa e crítica dos alunos, apresentar desafios, conduzir atividades para grupos distintos, orientar a solução de problemas, guiar os alunos para que assumam responsabilidades etc. Isto vai implicar numa mudança de paradigma na formação docente. O professor, ao planejar sua aula, deve ser capaz de motivar os alunos na aprendizagem de um tema, ao mesmo tempo em que pode organizar tarefas de modo que os alunos aprendam a participar em grupo.

Nesse novo modelo, deve o professor focar mais na sua formação pessoal, ao lado do conhecimento da matéria que vai ensinar e de sua preparação didática. Portanto, mais que ser um professor erudito e imbuído de técnicas de ensino, esse profissional deve ser capaz de estabelecer uma comunicação baseada na aceitação e no respeito na relação professor-aluno.

Para tanto, esse novo docente, demandado pela atual sociedade industrializada e globalizada, movida à informação e ao conhecimento, está diante de um dilema complexo, que é a escolha adequada para desenvolver um currículo. Segundo Sacristán e Gomez (1994) nessa situação existem pelo menos três considerações essenciais: os 
recursos físicos onde a aula se realiza; recursos didáticos demandados pelo currículo aos professores que nem sempre dispõe deles; e um grupo de alunos por possibilidades e necessidades concretas.

Já para Gagné (1974) há certas categorias de aprendizagem que um planejamento de ensino deve seguir, são elas: as habilidades intelectuais, estratégias cognitivas, informação verbal, destrezas motoras e atitudes. Segundo ele, diante de um mundo globalizado necessita-se educar com equidade e mentalidade crítica reflexiva, somente assim um ensino planejado produz resultados de aprendizagem.

Ainda Meirieu (1990) fez um esboço das competências demandadas para o que ele define como "a nova profissão". Essas se dividem em 10 grandes famílias: 1. Organizar e estimular situações de aprendizagem; 2. Gerar a progressão das aprendizagens; 3. Conceber e fazer com que os dispositivos de diferenciação evoluam; 4. Envolver o aluno em suas aprendizagens e no trabalho; 5. Trabalhar em equipe; 6. Participar da gestão da escola; 7. Informar e envolver os pais; 8. Utilizar as novas tecnologias; 9. Enfrentar os deveres e os dilemas éticos da profissão; 10. Gerar sua própria formação contínua.

Enquanto para Philippe Perrenoud (2004), o novo paradigma socioeconômico da sociedade contemporânea trouxe algumas inovações que já foram internalizadas pelos professores, e outras que outrora eram competências desenvolvidas apenas por outros profissionais:

É preciso reconhecer que os professores não possuem apenas saberes, mas também competências profissionais que não se reduzem ao domínio dos conteúdos a serem ensinados, e aceitar a idéia de que a evolução exige que todos os professores possuam competências antes reservadas aos inovadores ou àqueles que precisavam lidar com públicos difíceis.

A profissão de educador apresenta hoje um leque de aproximadamente 50 competências essenciais ao desempenho adequado ao novo modelo de sociedade pósmoderna. Sinais do novo tempo que implica estudo e pesquisa constantes.

\section{Conclusão}

Em vista disso, vê-se que o educador, desde a revolução Industrial, vem adequando seu desempenho na escola e dentro da sala de aula aos novos desafios da sociedade, e que cada época traz consigo suas demandas paradigmáticas, que implica no desenvolvimento de novas habilidades e competências, frutos de uma sociedade que tem buscado responder prontamente às suas necessidades. Dentro dessa dinâmica e complexidade que é a organização social contemporânea, a concepção de um ensino 
plasmado por competências e habilidades, parece ser o que de melhor se apresenta face a problemática de informar, formar e conscientizar às novas gerações do nosso tempo.

\section{Referências}

GAGNÉ, R. M. “The conditions of Learning”. $3^{\text {rd }}$ edition. Holt, Rinehart e Winston, 1974.

MEIRIEU, Ph. Enseigner, scenario pour un métier noveau. Paris:ESF, 1990.

SACRISTÁN, J. G.; Gómez, P. Compreender e Transformar o ensino. Tradução de ERNANI F. da Fonseca Rosa. Porto Alegre: Artmed, 1988.

UNESCO, Alianza Universidad. Aprender a ser. España, 1993.

, Declaracion de la Conferencia Mundial de Educación, La Habana, 1997.

, Declaración de la Conferencia Mundial de Educación, Paris, 2009.

PERRENOUD, Philippe. Avaliação: da excelência à regulação das aprendizagens. Porto Alegre: Artmed, 1999.

Três condições para aprender. In Os ciclos de aprendizagem: um caminho para combater o fracasso escolar. Porto Alegre: Artmed, 2004. p. 55-66. 